\title{
Preparation of Spherical Silica Based-Fillers with Zirconia for Dental Composite by Spray Pyrolysis
}

\author{
Takayuki Kodera* $^{*}$ \\ Department of Creative Engineering, National Institute of Technology, Tsuruoka College, 104, Sawada, Inooka, \\ Tsuruoka, Yamagata 997-8511, Japan \\ *Corresponding Author: kodera@tsuruoka-nct.ac.jp
}

\begin{abstract}
$\mathrm{SiO}_{2}-\mathrm{Y}_{2} \mathrm{O}_{3}$ stabilized $\mathrm{ZrO}_{2}$ (YSZ) nano-hybrid fillers were successfully prepared by spray pyrolysis process. The chemical and physical properties of $\mathrm{SiO}_{2}$-YSZ nano-hybrid fillers were characterized by powder X-ray diffraction (XRD), a field-emission scanning electron microscope (FESEM), and a transmission electron microscopy (TEM) using energy dispersive X-ray spectrometer (EDS). XRD revealed that the crystal phases of $\mathrm{SiO}_{2}$-YSZ nano-hybrid fillers were the phases of both amorphous $\mathrm{SiO}_{2}$ and tetragonal YSZ. $\mathrm{SiO}_{2}$-YSZ nano-hybrid fillers exhibited spherical morphology with approximately $1 \mu \mathrm{m}$. The flexural strengths of the dental composites as the property of filler were examined. The difference in the primary particle size of $\mathrm{SiO}_{2}-\mathrm{YSZ}$ nano-hybrid fillers was related to the difference in the flexural strengths. The $\mathrm{SiO}_{2}$-YSZ nano-hybrid fillers formed by the primary particles with approximately $90 \mathrm{~nm}$ exhibited high flexural strength of the dental composites. The flexural strength of the dental composites using that $\mathrm{SiO}_{2}-\mathrm{YSZ}$ nanohybrid fillers formed by the primary particles with approximately $90 \mathrm{~nm}$ was approximately $210 \mathrm{MPa}$.
\end{abstract}

Keywords: Composite filler, Dental composite, CAD/CAM resin, Spray pyrolysis, Filler.

\section{Introduction}

The resin composites have been widely used as dental filling materials ${ }^{1}$. However, flexural strength, compressive strength, and wear resistance of the resin composites are low for using with canines and posterior teeth ${ }^{(1-3)}$. Dental resin composites (dental composites) mainly consist of resin matrix and oxide fillers. The powder characteristics of oxide fillers contribute significantly to mechanical property such as the flexural strength. The flexural strength of front teeth is approximately $100 \mathrm{MPa}$. On the other hand, the flexural strengths of canines and posterior teeth range from approximately 200 to $500 \mathrm{MPa}$. $\mathrm{SiO}_{2}$ based-particles with $\mathrm{Al}_{2} \mathrm{O}_{3}, \mathrm{ZrO}_{2}, \mathrm{TiO}_{2}$, and $\mathrm{CaO}$ either alone or in combination have been usually used as fillers ${ }^{1}$. The flexural strengths of $\mathrm{SiO}_{2}$ and $\mathrm{Al}_{2} \mathrm{O}_{3}$ ceramics is approximately $120 \mathrm{MPa}$, respectively. Therefore, the flexural strengths of dental composites with $\mathrm{SiO}_{2}$ based-fillers with $\mathrm{Al}_{2} \mathrm{O}_{3}$ are lower than $120 \mathrm{MPa}$. It is known that the using of $\mathrm{ZrO}_{2}$ to $\mathrm{SiO}_{2}$ basedfillers is effective for improvement of mechanical properties of the dental composites ${ }^{(4-6)}$. The flexural strength and compressive strength of $\mathrm{ZrO}_{2}$ ceramics with tetragonal and cubic structure are higher performance than that of $\mathrm{ZrO}_{2}$ ceramics with monoclinic structure. The crystal phase of $\mathrm{ZrO}_{2}$ is monoclinic structure at room temperature. Tetragonal and cubic phases can be stabilized upon doping with trivalent ions such as $\mathrm{Y}^{3+(7,8)}$.

Spray pyrolysis is a versatile process that is used to synthesize fine oxide particles and fine metal particles ${ }^{(9)}$. Spray pyrolysis can convert a droplet of the starting solution into an oxide or metal particle at one step, and is a continuous process. The advantages of spray pyrolysis are that it allows to control of the particle size, particle size distribution, and particle morphology. In addition, fine particles with a homogeneous composition can be easily synthesized, because the starting solution components are kept in a droplet. The features of spray pyrolysis that can produce fine particles in one step and continuously is a great advantage for industrial powder production.

In this study, it tried to prepare $\mathrm{SiO}_{2}-\mathrm{Y}_{2} \mathrm{O}_{3}$ stabilized $\mathrm{ZrO}_{2}$ (YSZ) nano-hybrid fillers by spray pyrolysis in order to improve the flexural strength of the dental composites. The effect of starting materials and the surface micro- 
structures of particle on the flexural strength of the dental composites was investigated. The particle characteristics were also investigated.

\section{Experimental procedure}

\subsection{Preparation of the oxide fillers}

Spray pyrolysis ${ }^{(9)}$ was used to prepare $\mathrm{SiO}_{2}-\mathrm{YSZ}$ particles. $\mathrm{Si}\left(\mathrm{OC}_{2} \mathrm{H}_{5}\right)_{4}$ (TEOS) and three types of $\mathrm{SiO}_{2}$ sols were used as a silicon source. Average particle sizes of these $\mathrm{SiO}_{2}$ sols were 15, 35, and $95 \mathrm{~nm}$, respectively. $\mathrm{ZrO}\left(\mathrm{NO}_{3}\right)_{2} \cdot 2 \mathrm{H}_{2} \mathrm{O}$ and $\mathrm{Y}\left(\mathrm{NO}_{3}\right)_{3} \cdot 6 \mathrm{H}_{2} \mathrm{O}$ were used as the starting materials for YSZ. $\mathrm{ZrO}\left(\mathrm{NO}_{3}\right)_{2} \cdot 2 \mathrm{H}_{2} \mathrm{O}$ and $\mathrm{Y}\left(\mathrm{NO}_{3}\right)_{3} \cdot 6 \mathrm{H}_{2} \mathrm{O}$ were dissolved in the solution of $\mathrm{SiO}_{2}$ sols at room temperature. The molar ratio of the metal component ( $\mathrm{Si}: \mathrm{Zr}$ ) was set to $3: 1$ in the solution. The molar ratio of the metal component ( $\mathrm{Zr}: \mathrm{Y}$ ) was set to $97: 3$ in the solution. The concentration of the starting solutions was $0.1 \mathrm{~mol} / \mathrm{dm}^{3}$. The starting solutions were converted to mists using an ultrasonic nebulizer. Air was used as the carrier gas during the preparation of $\mathrm{SiO}_{2}-\mathrm{YSZ}$ particles. The generated mists were carried to an alumina tube that was heated by two electric furnaces, and then pyrolyzed. The flow rate of the carrier gas was $7 \mathrm{dm}^{3} / \mathrm{min}$. The temperature of an electric furnace in the drying zone were $400{ }^{\circ} \mathrm{C}$. The temperature of an electric furnace in the pyrolysis zone were $800{ }^{\circ} \mathrm{C}$. The precursor particles were continuously collected using a cyclone system. Furthermore, the precursor particles were calcined from 800 to $1100{ }^{\circ} \mathrm{C}$ for $2 \mathrm{~h}$ in an electric furnace under an air atmosphere in order to investigate the effect of the calcination temperature on the particle characteristics. A silane coupling agent was used to enhance the interfacial interactions between the resin matrix and the calcined particles. 3-methacryloxypropyl trimethoxysilane (3-MPS) was used as a silane coupling agent. 3-MPS has been adopted as an industry standard coupling agent ${ }^{1)}$. The surfacemodified particles were used as fillers.

\subsection{Characterization of the particles}

The crystal phase of the obtained particles was identified by powder X-ray diffraction (XRD, Rigaku, Mini Flex II) using $\mathrm{Cu} \mathrm{K} \alpha$ radiation. The particle size and morphology of the obtained particles were determined by using a fieldemission scanning electron microscope (FE-SEM, JEOL, JSM-7610F). In the FE-SEM images, 200 particles were randomly sampled to determine the average particle size. Chemical analysis of the calcined particles was carried out a transmission electron microscopy (TEM, JEOL, JEM-2100) using energy dispersive X-ray spectrometer (EDS, JEOL, JED-2300T).

\subsection{Preparation of the dental composites}

The dental composites were prepared in order to examine the flexural strength of the dental composites used the prepared fillers. The monomer urethane dimethylacrylate (UDMA, Sigma-Aldrich) was manually mixed to the monomer triethylene glycoldimethacrylate (TEGDMA, Sigma-Aldrich). The weight ratio of the monomer component (TEGDMA:UDMA) was set to 70:30. For the polymerization, $0.5 \mathrm{wt} \%$ camphorquinone (Sigma-Aldrich) as photo initiator was added. These monomers and camphorquinone were manually mixed in the dark, during 30 min. The fillers were manually blended with the monomers mixture by using a mortar and pestle, until obtaining a homogeneous paste, in the dark.

\subsection{Flexural tests of the dental composites}

The specimens $(25 \mathrm{~mm} \times 2 \mathrm{~mm} \times 2 \mathrm{~mm})$ for the flexural tests were prepared by filling a stainless steel split mold with uncured dental composites, following the ISO 10477. Then, the specimens were photo-cured by applying light (375-495 $\mathrm{nm})$ for $60 \mathrm{~s}$. The flexural strength of the specimens was measured using a three-point bending test. All tests were carried out at a cross-head speed of $1.0 \pm 0.3 \mathrm{~mm} / \mathrm{min}$ until fracture occurred. The load was applied to the center of the specimens placed on supports with $20 \mathrm{~mm}$ span. The flexural strength $(\sigma)$ was calculated by the following equations:

$$
\sigma=\frac{3 F l}{2 b h^{2}}
$$

where $F$ is the maximum load exerted at the fracture point, $l$ is support span length, $b$ and $h$ are the width and height of the specimen measured prior to test.

\section{Results and discussion}

\subsection{Particle characteristics}

The effect of changing the calcination temperature on the crystal phases of the obtained particles was investigated. The calcination temperatures were from 800 to $1100^{\circ} \mathrm{C}$. The crystal phases of the obtained particles were observed by using the XRD. Figure 1 shows the XRD patterns of the precursor particles obtained from the $\mathrm{SiO}_{2}$ sol with $95 \mathrm{~nm}$. 


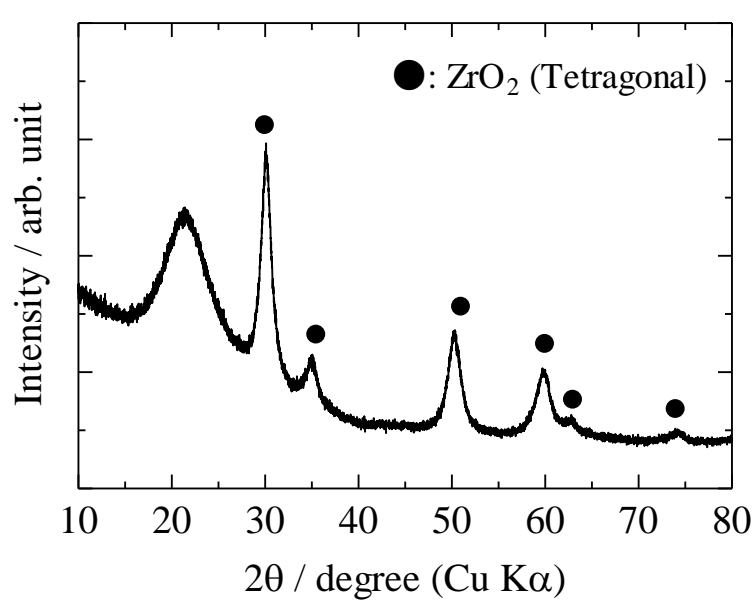

Fig. 1. XRD patterns of the precursor particles obtained from the $\mathrm{SiO}_{2}$ sol with $95 \mathrm{~nm}$.

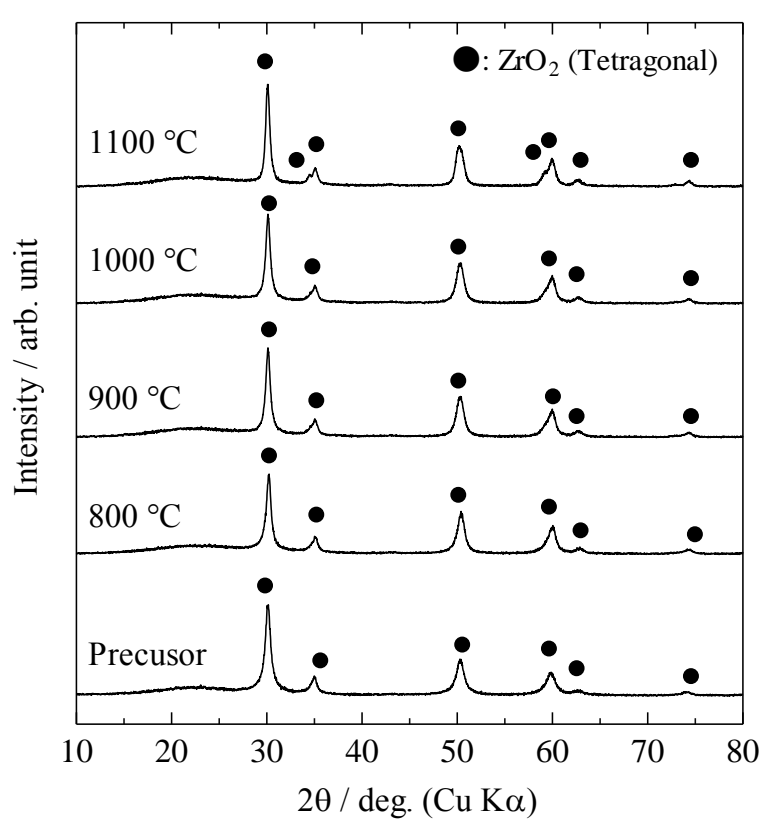

Fig. 2. XRD patterns of the precursor particles and calcined particles that obtained from the $\mathrm{SiO}_{2}$ sol with 95 nm.

The broad halo due to amorphous $\mathrm{SiO}_{2}$ was observed at 20$30^{\circ}$. The other diffraction patterns were agreement with the diffraction patterns of tetragonal $\mathrm{ZrO}_{2}$, and the other phases such as $\mathrm{ZrO}\left(\mathrm{NO}_{3}\right)_{2} \cdot 2 \mathrm{H}_{2} \mathrm{O}, \mathrm{Y}\left(\mathrm{NO}_{3}\right)_{3} \cdot 6 \mathrm{H}_{2} \mathrm{O}$, and monoclinic phase were not observed. The crystal phase of $\mathrm{ZrO}_{2}$ is monoclinic structure at room temperature. Therefore, the doping of yttrium led to stabilization of tetragonal structure at room temperature ${ }^{(7,8)}$. Figure 2 shows the XRD patterns of
Precursor

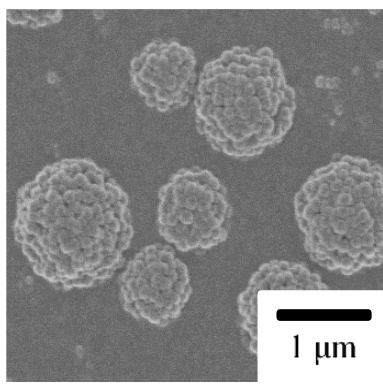

$1100^{\circ} \mathrm{C}$

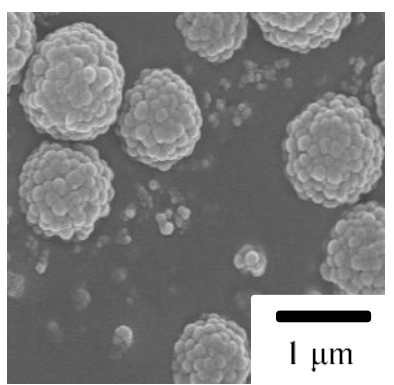

Fig. 3. FE-SEM images of the precursor particles and the calcined particles that obtained from the $\mathrm{SiO}_{2}$ sol with $95 \mathrm{~nm}$.

the precursor particles and the calcined particles that obtained from the $\mathrm{SiO}_{2}$ sol with $95 \mathrm{~nm}$. The crystal phases of the calcined particles were that of amorphous $\mathrm{SiO}_{2}$ and tetragonal $\mathrm{ZrO}_{2}$, and the other phases were not observed. This suggested that the composite particles of $\mathrm{SiO}_{2}$ and YSZ were obtained. The crystallinity of YSZ phase became high with increasing calcination temperature. Regardless of the type of silicon source as starting material, the crystal phases of the calcined particles that obtained from TEOS and the $\mathrm{SiO}_{2}$ sols $(15,35 \mathrm{~nm})$ were also that of amorphous $\mathrm{SiO}_{2}$ and tetragonal $\mathrm{ZrO}_{2}$.

Figure 3 shows the FE-SEM images of the precursor particles and $\mathrm{SiO}_{2}$-YSZ particles calcined at $1100{ }^{\circ} \mathrm{C}$ that obtained from the $\mathrm{SiO}_{2}$ sol with $95 \mathrm{~nm}$. The precursor particles and $\mathrm{SiO}_{2}$-YSZ particles calcined at $1100{ }^{\circ} \mathrm{C}$ were spherical particles and non-aggregated. When the $\mathrm{SiO}_{2}$ sol with $95 \mathrm{~nm}$ were used as a silicon source, the primary particles with approximately $90 \mathrm{~nm}$ aggregated and the spherical secondary particles were formed, regardless of the calcination temperature. It was found that the changing the calcination temperature do not effect on the surface morphology of the calcined particles when the calcination temperature ranged from 800 to $1100{ }^{\circ} \mathrm{C}$.

Figure 4 shows the FE-SEM images of $\mathrm{SiO}_{2}$-YSZ particles calcined at $1100{ }^{\circ} \mathrm{C}$, when TEOS and three types of $\mathrm{SiO}_{2}$ sols $(15,35$, and $95 \mathrm{~nm})$ were used as a silicon source. $\mathrm{SiO}_{2}-\mathrm{YSZ}$ particles calcined at $1100{ }^{\circ} \mathrm{C}$ exhibited spherical morphology with approximately $1 \mu \mathrm{m}$, regardless of the type of silicon source. When the $\mathrm{SiO}_{2}$ sols were used as a silicon source, the primary particles aggregated and the spherical secondary particles were formed. The primary particle sizes of $\mathrm{SiO}_{2}$-YSZ particles obtained from the $\mathrm{SiO}_{2}$ sols was almost the same as the particle sizes of the $\mathrm{SiO}_{2}$ sols used as a silicon source. 


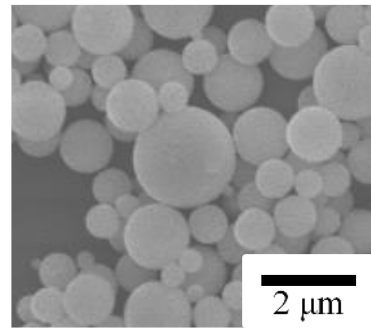

$\mathrm{SiO}_{2}$ sols with $30 \mathrm{~nm}$

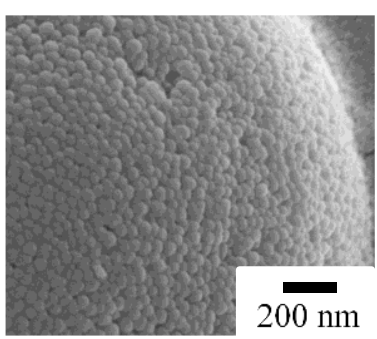

$\mathrm{SiO}_{2}$ sols with $15 \mathrm{~nm}$

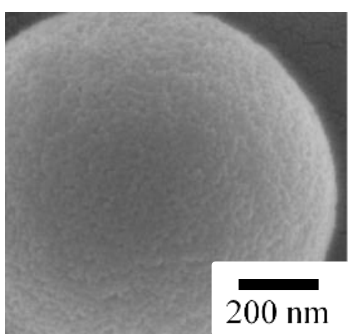

$\mathrm{SiO}_{2}$ sols with $95 \mathrm{~nm}$

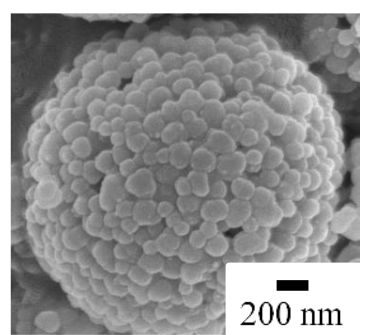

Fig. 4. FE-SEM images of $\mathrm{SiO}_{2}-\mathrm{YSZ}$ particles calcined at $1100{ }^{\circ} \mathrm{C}$.

Figure 5 shows the scanning TEM (STEM) image of $\mathrm{SiO}_{2}-\mathrm{YSZ}$ secondary particle calcined at $1100{ }^{\circ} \mathrm{C}$ that obtained from the $\mathrm{SiO}_{2}$ sol with $95 \mathrm{~nm}$, and also STEM-EDS elemental mapping of $\mathrm{SiO}_{2}$-YSZ particles. This analysis elucidates the selective $\mathrm{Si}$ and $\mathrm{Zr}$ segregation within the particles. Si was distributed inside the primary particles. On the other hand, $\mathrm{Zr}$ was distributed on the surface of the primary particles. This suggested that the spherical secondary particles were formed by $\mathrm{SiO}_{2}-\mathrm{YSZ}$ primary particles with nano-sized.

\subsection{Flexural property of the dental composites}

The flexural strengths of the dental composites as the property of filler were examined. Figure 6 shows the flexural strengths of the dental composites. $\mathrm{SiO}_{2}$-YSZ particles calcined at $1100{ }^{\circ} \mathrm{C}$ were used as fillers. $\mathrm{SiO}_{2}$-YSZ particles calcined at $1100{ }^{\circ} \mathrm{C}$ were surface-modified by a silane coupling agent (3-MPS). In order to allow a high particle packing $\left(>60 \mathrm{wt} \%\right.$ ) to the monomers, $\mathrm{SiO}_{2}$-YSZ surfacemodified nanoparticles with approximately $90 \mathrm{~nm}$ were also used as fillers $\left.{ }^{(2,} 1011\right)$. $\mathrm{SiO}_{2}$-YSZ surface-modified nanoparticles was blended with $\mathrm{SiO}_{2}$-YSZ surface-modified particles calcined at $1100{ }^{\circ} \mathrm{C}$. The weight ratio of the filler component $\left(\mathrm{SiO}_{2}-\mathrm{YSZ}\right.$ surface-modified particles: $\mathrm{SiO}_{2}-\mathrm{YSZ}$ surface-modified nanoparticles) was set to 70:30. The total filler contents were $79 \mathrm{wt} \%$ in each the dental composites, respectively. When $\mathrm{SiO}_{2}$-YSZ surface-modified particles

(a)

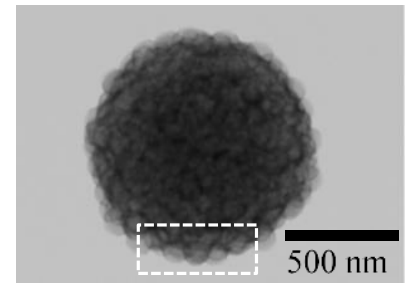

(b)

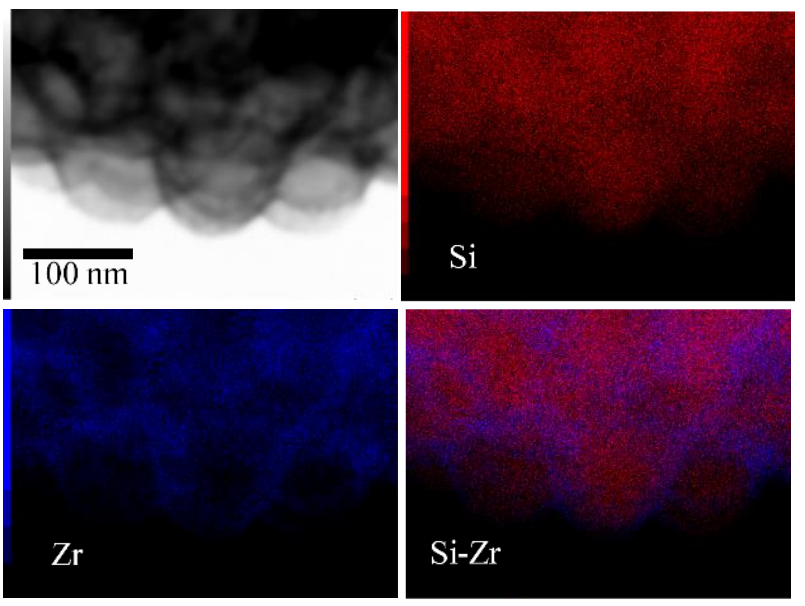

Fig. 5. (a) STEM image of $\mathrm{SiO}_{2}-\mathrm{YSZ}$ secondary particle calcined at $1100{ }^{\circ} \mathrm{C}$ that obtained from the $\mathrm{SiO}_{2}$ sol with $95 \mathrm{~nm}$. (b) STEM image, and corresponding STEM-EDS maps elucidating the distribution of $\mathrm{Si}, \mathrm{Zr}$, Si and $\mathrm{Zr}$ over the area within the frame in Fig. 5(a).

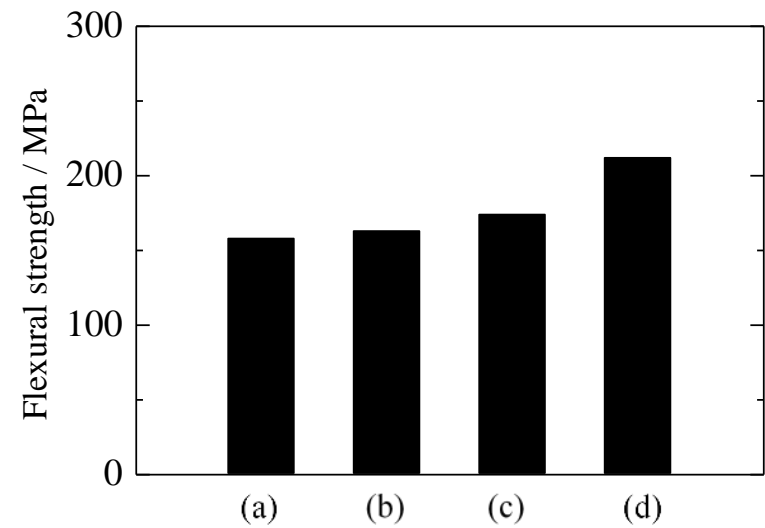

Fig. 6. Flexural strengths of the dental composite. The calcined particles obtained from (a) TEOS, (b) $\mathrm{SiO}_{2}$ Sol with $15 \mathrm{~nm}$, (c) $\mathrm{SiO}_{2}$ Sol with $35 \mathrm{~nm}$, and (d) $\mathrm{SiO}_{2}$ Sol with $95 \mathrm{~nm}$ were used as fillers.

obtained from TEOS and the $\mathrm{SiO}_{2}$ sol with $15 \mathrm{~nm}$ were used as fillers, the flexural strengths of the dental composites were both approximately $160 \mathrm{MPa}$. When $\mathrm{SiO}_{2}$-YSZ surface- 
modified particles obtained from the $\mathrm{SiO}_{2}$ sol with $35 \mathrm{~nm}$ were used as filler, the flexural strengths of the dental composites increased to approximately $170 \mathrm{MPa}$. Furthermore, the flexural strengths of the dental composites increased to approximately $210 \mathrm{MPa}$, when $\mathrm{SiO}_{2}-\mathrm{YSZ}$ surface-modified particles obtained from the $\mathrm{SiO}_{2}$ sol with $95 \mathrm{~nm}$ were used as filler. It was found that the flexural strengths of the dental composites increased as the primary particle size of fillers increased. It is considered that the surface roughness of $\mathrm{SiO}_{2}-\mathrm{YSZ}$ particles contributed to the strength of the anchoring effect at the interface between fillers and resin, and this resulted in increasing flexural strengths.

\section{Conclusions}

$\mathrm{SiO}_{2}$-YSZ spherical particles were successfully prepared by spray pyrolysis process. $\mathrm{SiO}_{2}$-YSZ spherical particles were the secondary particles with approximately 1 $\mu \mathrm{m}$ formed by $\mathrm{SiO}_{2}-\mathrm{YSZ}$ primary particles and were nonaggregated. The calcination temperature between 800 and $1100^{\circ} \mathrm{C}$ influenced the crystallinity and did not the surface microstructure of particle. XRD revealed that the homogeneous crystal phase of $\mathrm{SiO}_{2}$-tetragonal $\mathrm{YSZ}$ obtained by calcining from 800 to $1100^{\circ} \mathrm{C}$. XRD, FE-SEM observation, and EDS analysis indicated that $\mathrm{SiO}_{2}-\mathrm{YSZ}$ particles had a hybrid structure by $\mathrm{SiO}_{2}$ and $\mathrm{YSZ}$ at a nanoorder. The difference in the primary particle size of $\mathrm{SiO}_{2}$ YSZ fillers influenced the flexural strengths of the dental composites. The flexural strengths of the dental composites using $\mathrm{SiO}_{2}$-YSZ fillers increased from $160 \mathrm{MPa}$ to $210 \mathrm{MPa}$ as the primary particle size of fillers increased from approximately $10 \mathrm{~nm}$ or less than to approximately $90 \mathrm{~nm}$.

\section{Acknowledgment}

This work was supported by JSPS KAKENHI Grant Number JP18K09631.

\section{References}

(1) Eric Habib, Ruili Wang, Yazi Wang, Meifang Zhu, and X. X. Zhu: "Inorganic Fillers for Dental Resin Composites: Present and Future", Journal of ACS Biomaterials Science \& Engineering, Vol. 2, pp. 1-11, 2016

(2) Edina Lempel, Ákos Tóth, Tamás Fábián, Károly Krajczár, and József Szalma: "Retrospective Evaluation of Posterior Direct Composite Restorations: 10-Year Findings", Dental materials, Vol. 31, pp. 115-122, 2015

(3) Xinyi Wu, Shiqi Dai, Ying Chen, Feng He, Haifeng Xie, Chen Chen: "Reinforcement of Dental Resin Composite via Zirconium Hydroxide Coating and Phosphate Ester Monomer Conditioning of Nano-zirconia Fillers", Journal of the Mechanical Behavior of Biomedical Materials, Vol. 94, pp. 32-41, 2019

(4) Abdolhamid Alhavaz, Maryam Rezaei Dastjerdi, Arman Ghasemi, Azade Ghasemi, and Abolfazl Alizadeh Sahraei: "Effect of Untreated Zirconium Oxide Nanofiller on the Flexural Strength and Surface Hardness of Autopolymerized Interim Fixed Restoration Resins", Journal of Esthetic and Restorative Dentistry, Vol. 29, pp. 264-269, 2017

(5) Guangqing Guo, Yuwei Fan, Jian-Feng Zhang, Joseph L. Hagan, and Xiaoming Xu: "Novel Dental Composites Reinforced with Zirconia-Silica Ceramic Nanofibers", Dental Materials, Vol. 28, pp. 360-368, 2012

(6) Umesh Vishnu Hambire, and Vipin Kumar Tripathi: "Optimisation of Compressive Strength in Zirconia Nanoclusters of the Bis-GMA \& TEGDMA Based Dental Composites", Procedia Engineering, Vol. 51, pp. 494-500, 2013

(7) Ping Li, I-Wei Chen, and James E. Penner-Hahn: "XRay-Absorption Studies of Zirconia Polymorphs. I. Characteristic Local Structures", Physical Review B, Vol. 48, pp. 10063-10073, 1993

(8) Ping Li, I-Wei Chen, and James E. Penner-Hahn: "Effect of Dopants on Zirconia Stabilization-An X-Ray Absorption Study: I, Trivalent Dopants", Jounal of American Ceramic Society, Vol. 77, pp. 118-128, 1994

(9) Gary L. Messing, Shi-Chang Zhang, and Gopal V. Jayanthi: "Ceramic Powder Synthesis by Spray Pyrolysis", Journal of the American Ceramic Society, Vol. 76, pp. 2707-2726, 1993

(10) Luc D. Randolph, William M. Palin, Gaëtane Leloup, and Julian G. Leprince: "Filler Characteristics of Modern Dental Resin Composites and their Influence on Physico-Mechanical Properties", Dental Materials, Vol. 32, pp. 1586-1599, 2016

(11) Sumita B. Mitara, Dong Wu, and Brian N. Holmes: "An Application of Nanotechnology in Advanced Dental Materials", The Journal of the American Dental Association, Vol. 134, pp. 1382-1390, 2003 